\title{
Liposomes co-loaded with ursolic acid and ginsenoside Rg3 in the treatment of hepatocellular carcinoma
}

\author{
Bin Wang ${ }^{1}$, Chenjian Zhou ${ }^{2}$, Qiaoqiao $\mathrm{Xu}^{1}$ and Yu Lin ${ }^{1} \square$ \\ 1Department of Pharmaceutical, The First Affiliated Hospital of Wenzhou Medical University, Wenzhou, Zhejiang 325000, China; ${ }^{2}$ Department of \\ Pharmaceutical, Wenzhou Central Hospital, Wenzhou, Zhejiang 325000, China
}

Objective: Liposomes co-loaded with ursolic acid and ginsenoside $\mathrm{Rg} 3$ (UA+Rg3-LIP) were prepared to study their effects on the proliferation, apoptosis and cell cycle of hepatocellular carcinoma (HCC) cells. Methods: Liposomes were prepared by reverse evaporation, and then UA+Rg3-LIP were prepared by the $\mathrm{pH}$ gradient method, and followed by liposome characterization. Next, the effects of UA+Rg3-LIP on the proliferation, apoptosis and cell cycle of HepG2 cells were investigated by MTT method and flow cytometry at the cell level. Results: The entrapment efficiency of UA in UA+Rg3-LIP was $78.52 \%$ and that of $\mathrm{Rg} 3$ was $71.68 \%$, as assayed by low-temperature ultracentrifugation. The in vitro release rates of UA+Rg3-LIP and UA+Rg3 detected by the dialysis membrane method were 1-10 $\mathrm{h}$. The release rate of UA+Rg3 was close to $100 \%$; that of UA+Rg3-LIP was decreased after $10 \mathrm{~h}$ and approached $100 \%$ after $24 \mathrm{~h}$. It was further confirmed by cell experiments that UA+Rg3LIP could significantly reduce cells' viability while at the same time increase their apoptosis rate and raise the proportion of cells in the G0/G1 phase. Conclusion: Liposomes co-loaded with ursolic acid and ginsenoside Rg3 could affect cell proliferation, apoptosis and cell cycle, thus slowing down the in vitro drug release ability of HCC.

Keywords: ursolic acid; ginsenoside Rg3; liposome; hepatocellular carcinoma; HepG2; in vitro drug release

Received: 09 February, 201; revised: 07 May, 2021; accepted: 17 May, 2021; available on-line: 03 November, 2021

छe-mail: linyu20002020@126.com

Abbreviations: HCC, hepatocellular carcinoma; UA, ursolic acid

\section{INTRODUCTION}

Hepatocellular carcinoma (HCC) is a common tumor with high malignancy, low cure rate, and a mortality rate as high as $90 \%$ (Jiao et al., 2017). At present, the preferred methods for the treatment of HCC are still surgical resection or chemotherapy, but patients have a high recurrence rate and a low survival rate after surgery (Elmore, 2007).

In recent years, it has been found that natural Chinese herbal plants can improve the body's immunity and have certain anti-tumor activity. Ursolic acid (UA) (Fig. 1A) is a ursolane-type pentacyclic triterpenoid acid that is ubiquitous in the leaves and fruits of natural medicinal plants, such as the leaves of Ligustrum lucidum Ait., Eriobotrya japonica (Thunb.) Lindl., Paulownia tomentosa (Thunb.) Steud., and Ilexrotunda Thunb., Actostaphylos wvaursi (L.) Spreng, the whole plant of Prunella vulgaris L., and fruits with waxy protection, like apples, pears, and plums (Zhan \& Yi, 2008; Ngo et al., 2011). It possesses extensive pharmacological activities and especially has favorable effects on human diseases (Laszczyk, 2009). Research has shown that UA has a variety of biological effects, such as sedation, anti-inflammation, antibiosis, anti-diabetes, hypoglycemia, anti-proliferation, pro-apoptosis and anti-angiogenesis in in vitro and in vivo cancer models (Shanmugam et al., 2012). In addition, UA can inhibit HepG2 cell growth (Yie et al., 2015), and increase apoptotic death in HCC cells (Kim et al., 2019).

Ginsenoside Rg3 (Rg3) (Fig. 1B), a tetracyclic triterpenoid saponin present in the natural medicine ginseng, is one of the main active components of ginseng (Hua \& Hua, 2012). Studies have shown that ginsenoside Rg3 has a certain inhibitory effect on many malignant tumors, such as the lung cancer, gastric cancer, intestinal cancer, liver cancer, and breast cancer, while it can also enhance the immune function in patients (Zhang et al., 2006; Lu et al., 2008; He et al., 2011). Although UA and Rg3 have been more experimentally studied in inhibiting the development of various tumors, the poor water solubility and low tumor targeting of these two drugs limit their efficacy (Lee et al., 2014; Khan et al., 2018). It has been reported that liposomal carriers can significantly improve the delivery efficiency of non-oral administration of hydrophobic drugs (Musacchio \& Torchilin, 2011). The combination of liposomal carriers has an excellent anti-tumor effect, good targeting, low toxicity and small side effects (Jiang et al., 2018). A study by Sun and others (Sun et al., 2020) confirmed that hyaluronic acid (HA)-coated nanostructured lipid carriers (NLC) simultaneously loaded with oleanolic acid (OA), UA and Rg3 have more potent antitumor activity than $5-\mathrm{Fu}$ in liver cancer. However, specific functional studies have not been reported.

Therefore, based on the synergistic effect of multicomponents of traditional Chinese medicine, UA and $\mathrm{Rg} 3$ were encapsulated in liposomes to prepare a carrier
A

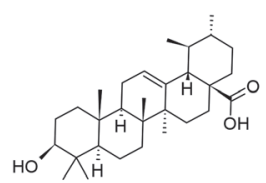

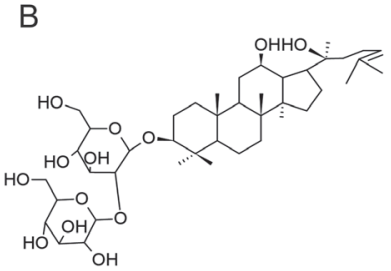

Ginsenoside Rg3
Figure 1. The chemical structures of Ursolic acid (A) and Ginsenoside $\mathrm{Rg} 3$ (B) 
for the two components (UA+Rg3-LIP) in this study. We also chose an artificial intestinal fluid to simulate the intestinal environment to investigate the in vitro drug release of $\mathrm{UA}+\mathrm{Rg} 3-\mathrm{LIP}$ on $\mathrm{HCC}$ and its effects on HepG2 cell proliferation, apoptosis and cell cycle, so as to provide a reference basis for the research and development of insoluble multi-component drug delivery system of traditional Chinese medicine for the treatment of HCC.

\section{MATERIALS AND METHODS}

\section{Cell line and treatment}

The human hepatocellular carcinoma cell line HepG2 was purchased from the Cell Bank of the Chinese Academy of Sciences (Shanghai, China), which was cultured in the DMEM medium containing 10\% fetal bovine serum (FBS) and two antibiotics $(100 \mathrm{U} / \mathrm{ml}$ penicillin and streptomycin), in a $5 \% \mathrm{CO}_{2}$ incubator at $37^{\circ} \mathrm{C}$. The experimental groups were divided based on the concentration of UA+Rg3-LIP as follows: Control group (without $\mathrm{UA}+\mathrm{Rg} 3-\mathrm{LIP}$ intervention in HepG2 cells), $0.25 \mathrm{mg} /$ $\mathrm{mL}$ group (with $0.25 \mathrm{mg} / \mathrm{mL} \mathrm{UA}+\mathrm{Rg} 3$-LIP intervention in HepG2 cells), $0.5 \mathrm{mg} / \mathrm{mL}$ group (with $0.5 \mathrm{mg} / \mathrm{mL}$ $\mathrm{UA}+\mathrm{Rg} 3-\mathrm{LIP}$ intervention in HepG2 cells), and $1 \mathrm{mg} /$ $\mathrm{mL}$ group (with $1 \mathrm{mg} / \mathrm{mL} \mathrm{UA}+\mathrm{Rg} 3-\mathrm{LIP}$ intervention in HepG2 cells).

\section{Reagents}

UA and MT'T kit were purchased from Sigma, USA; ginsenoside $\mathrm{Rg} 3$ was purchased from Ruijin Biotechnology Co., Ltd.; phospholipids, cholesterol and DMEM medium were all purchased from Beijing Solarbio Technology Co., Ltd.; fetal bovine serum was purchased from Zhejiang Tianhang Biotechnology Co., Ltd.; trypsin was purchased from Amresco; AnnexinV-FITC/PI apoptosis kit was purchased from Nanjing KeyGEN BioTECH Corp., Ltd; and artificial intestinal fluid was obtained according to the methods in the literature (Commission, 2015).

\section{Preparation of UA+Rg3-LIP}

Liposomes were prepared according to the methods described in (Ou et al., 2011). That is, lecithin, cholesterol and DSPE-PEG-GA were dissolved in ether. UA and ginsenoside $\mathrm{Rg} 3$ were dissolved in ethyl alcohol. After being mixed well, the mixture was injected at a constant speed into $20 \mathrm{~mL}$ of PBS at $65^{\circ} \mathrm{C}$ in a water bath, then placed on a constant-temperature magnetic stirrer to stir slowly and uniformly, and passed through a $0.8 \mu \mathrm{m}$ filter membrane. After that, the liposomes were kept away from light for 24 hours, dialyzed against distilled water for another 48 hours and finally lyophilized and stored. At room temperature, the particle size and surface potential of an appropriate amount of UA+Rg3-LIP and liposomes (LIP) were measured by confocal microscopy and potentiometric analyzer after 50 -fold dilution with distilled water.

\section{Entrapment efficiency of UA+Rg3-LIP}

The entrapment efficiency of liposomes co-loaded with UA and $\operatorname{Rg} 3$ was determined according to the method described in (Ma et al., 2019). Briefly, six milliliters of co-loaded liposomes were taken for ultracentrifugation and placed in six tubes for ultra-high speed centrifuges. After being sealed, they were centrifuged in an ultra-high speed centrifuge at $3000 \mathrm{r} / \mathrm{min}$ for $30 \mathrm{~min}$. Afterwards, the drug-loaded liposomes precipitated to the bottom of the centrifuge tubes, and the free drug without being encapsulated by phospholipids was present in the supernatant. Finally, concentration of the drug in the supernatant was determined and the entrapment efficiency was then calculated.

\section{In vitro release rate}

The in vitro release rate was determined according to the methods described in (Wang, 2010). $1.000 \mathrm{~g}$ of the sample was accurately weighed and placed in a dialysis bag with both ends tightly tied to remove bubbles. The bag was tied to the lower end of the stirring paddle and immersed in $500 \mathrm{~mL}$ of PBS ( $\mathrm{pH}$ 6.5) dialysis medium containing $50 \%$ ethanol by volume fraction. It was rotated at a speed of $50 \mathrm{rpm} / \mathrm{min}$ in a circulating water bath $\left(37^{\circ} \mathrm{C}\right) .1 \mathrm{~mL}$ of the sample was taken at time points of $0.25,0.5,1,4,8,10,15,24$ and $48 \mathrm{~h}$, while in the meantime the same amount of isothermal dialysis medium was added, to determine the liposome drug content and calculate the cumulative release amount Q. The calculation formula was: $\mathrm{Q}(\%)=$ (cumulative drug concentration in the release solution at each time point $\times$ volume of release medium/liposome drug content) $\times 100 \%$. In artificial intestinal fluid medium, the release data of berberine sulfate were fitted with zero-order and first-order kinetic equation, as well as the Higuchi equation for UA+Rg3LIP (Commission, 2015).

\section{MTT assay}

HepG2 cells in the logarithmic growth phase were inoculated on a 96-well culture plate $(100 \mu \mathrm{L} /$ well $)$ with $5 \times 10^{4}$ cells $/ \mathrm{mL}$, and were cultured under $5 \% \mathrm{CO}_{2}$ at $37^{\circ} \mathrm{C}$. After the cells in each well were completely adherent, they were treated with $0.25 \mathrm{mg} / \mathrm{mL}, 0.5 \mathrm{mg}$ / $\mathrm{mL}$ and $1 \mathrm{mg} / \mathrm{mL}$ of UA+Rg3-LIP for $48 \mathrm{~h}$ and then cultured for another $12,24,48$, and $72 \mathrm{~h}$, when $10 \mu \mathrm{L}$ of $5 \mathrm{mg} / \mathrm{mL}$ MTT solution was added to each well, as previously described (Jiang et al., 2011). Finally, after $4 \mathrm{~h}$ culture in the $\mathrm{CO}_{2}$ incubator, DMSO $(100 \mu \mathrm{L} /$ well $)$ was added to dissolve the formed purple crystals. The 570 $\mathrm{nm}$ wavelength absorbance value (OD) of each well was detected by a microplate reader.

\section{Cell apoptosis and cell cycle}

For the cell apoptosis assay, HepG2 cells were treated for $48 \mathrm{~h}$ and then collected by centrifugation at $1500 \mathrm{rpm}$ for $5 \mathrm{~min}$. Cells were stained with AnnexinVFITC/PI at $4^{\circ} \mathrm{C}$ for $30 \mathrm{~min}$. The apoptosis rate was measured with the FACSCalibur Flow Cytometer (Becton Dickinson, USA), and analyzed by using the FlowJo software.

Cell cycle was detected using PI staining. After $48 \mathrm{~h}$ of incubation, cells were collected and fixed in precooled $70 \%$ ethanol, and kept at $4^{\circ} \mathrm{C}$ overnight. Subsequently, the cells were washed and stained with PI for $30 \mathrm{~min}$ in the dark at room temperature. The cells were then analyzed with the FACSCalibur Flow Cytometer.

\section{Statistical analysis}

All experimental data were statistically analyzed with the SPSS 26.0 software, and expressed as mean \pm standard deviation (S.D.). Comparisons between two groups (when there were only two groups) were analyzed by ttest, while pairwise comparisons among multiple groups 
Table 1. Characteristics of liposomes: particle size, zeta-potential and entrapment efficiency $(n=3)$

\begin{tabular}{|c|c|c|c|c|}
\hline Group & Size (nm) & zeta-potential (mV) & $\mathrm{EE} \%(\mathrm{UA})$ & $\mathrm{EE} \%(\mathrm{Rg} 3)$ \\
\hline UA+Rg3-LIP & $181.64 \pm 4.08$ & $-33.35 \pm 1.49$ & $78.52 \%$ & $71.68 \%$ \\
\hline LIP & $163.31 \pm 4.05$ & $-18.43 \pm 2.11$ & - & - \\
\hline
\end{tabular}

$\mathrm{EE}$, entrapment efficiency.

Table 2. Results of fitting models of in vitro release

\begin{tabular}{lcc}
\hline Item & Mathematical model & Fitting equation \\
\hline & 0 order & $\mathrm{Q}=3.322 \mathrm{t}+33.317$ \\
UA+Rg3-LIP & First order & $\mathrm{Q}=98.16\left(1-\mathrm{e}^{-0.166 t)}\right.$ \\
& Higuchi & $\mathrm{Q}=18.929 \mathrm{t}^{1 / 2}+12.893$ \\
\hline
\end{tabular}

were analyzed by adopting one-way analysis of variance. $P<0.05$ indicated that the difference was statistically significant.

\section{RESULTS}

\section{Characteristics of UA+Rg3-LIP}

As shown in Table 1 , the particle size of $\mathrm{UA}+\mathrm{Rg} 3$ LIP was $181.7 \pm 4.36 \mathrm{~nm}$ and that of LIP was $163.5 \pm 3.92$ $\mathrm{nm}$, which were measured by confocal microscopy. The surface potential of UA+Rg3-LIP detected by the potential analyzer was $-33.7 \pm 1.48 \mathrm{mV}$, and that of LIP was $-18.5 \pm 2.17 \mathrm{mV}$. Moreover, the results of low-temperature ultracentrifugation revealed that the entrapment efficiency of UA and $\mathrm{Rg} 3$ in UA+Rg3-LIP were $78.52 \%$ and $71.68 \%$, respectively.

\section{In vitro release properties of UA+Rg3-LIP}

The experimental results with the dialysis membrane method showed that at $1-10 \mathrm{~h}$, the in vitro release rates of $\mathrm{UA}+\mathrm{Rg} 3$-LIP and $\mathrm{UA}+\mathrm{Rg} 3$ were relatively fast. The release rate of $\mathrm{UA}+\operatorname{Rg} 3$ was close to $100 \%$ at $12 \mathrm{~h}$; and, the in vitro release rate of UA+Rg3-LIP was decreased after $10 \mathrm{~h}$ but approached $100 \%$ after $24 \mathrm{~h}$ (Fig. 2). Furthermore, the fitting test showed that the release behavior of $\mathrm{UA}+\mathrm{Rg} 3-\mathrm{LIP}$ and $\mathrm{UA}+\mathrm{Rg} 3$ conformed to the first-order kinetic equation, and the best model for $\mathrm{UA}+\mathrm{Rg} 3$-LIP was the Higuchi equation (Table 2).

\section{Effect of UA+Rg3-LIP on proliferation of HepG2 cells}

MT'T results (Fig. 3) demonstrated that when compared to the Control group, the proliferation rates of

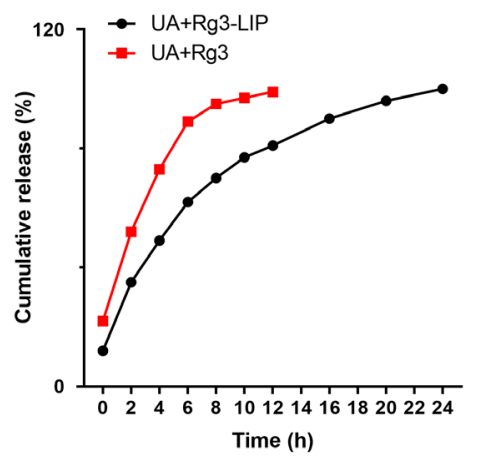

Figure 2. Drug release curves of UA+Rg3-LIP and UA+Rg3 in the artificial intestinal fluid medium cells in the $0.25 \mathrm{mg} / \mathrm{mL}, 0.5 \mathrm{mg} / \mathrm{mL}$ and $1 \mathrm{mg} / \mathrm{mL}$ groups were obviously decreased in a concentrationdependent manner, which confirmed that the inhibitory effect of UA+Rg3-LIP on proliferation of HepG2 cells was enhanced over time.

\section{Effects of UA+Rg3-LIP on apoptosis rate and cell cycle of HepG2 cells}

The flow cytometry analysis indicated that when compared to the Control group, the apoptosis rates of cells in the $0.25 \mathrm{mg} / \mathrm{mL}, 0.5 \mathrm{mg} / \mathrm{mL}$ and $1 \mathrm{mg} / \mathrm{mL}$ groups were remarkably increased (Fig. 4A), with an increase in cell proportion in the G0/G1 phase and a decrease of those in the $\mathrm{S}$ phase, in a concentration-dependent manner (Fig. 4B), implying that UA+Rg3-LIP could significantly promote apoptosis of the HepG2 cells and inhibit the cell cycle.

\section{DISCUSSION}

HCC is one of the common malignant tumors, and at present mainly occurs in the Asia-Pacific region (Lui, 2011). Although chemotherapy is one of the most widely studied methods in anticancer therapy, its efficacy and safety remain a major concern because of its serious side effects. In recent years, research on the use of natural herbal plants as anti-cancer drugs has gradually increased, and traditional Chinese medicine has played an essential role in the comprehensive treatment of cancer.

Multiple studies show that UA can control the growth, apoptosis and differentiation of HepG2 cells, with inhibition of their proliferation in a concentration-

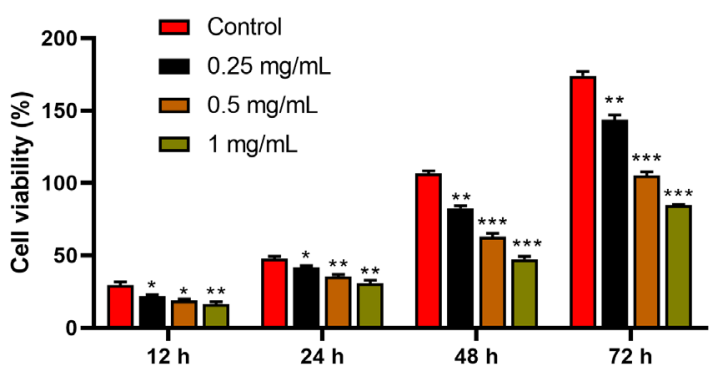

Figure 3. Effect of different concentrations of UA+Rg3-LIP on proliferation of the HepG2 cells.

After being treated with different concentrations of UA+Rg3-LIP $(0.25 \mathrm{mg} / \mathrm{mL}, 0.5 \mathrm{mg} / \mathrm{mL}$, and $1 \mathrm{mg} / \mathrm{mL})$, HepG2 cell viability was detected after $12,24,48$, and $72 \mathrm{~h}$ by the MTT assay. ${ }^{*} \mathrm{P}<0.05$ vs Control group; ${ }^{* *} P<0.01$ vs Control group; ${ }^{* *} P<0.001$ vs Control group 
A
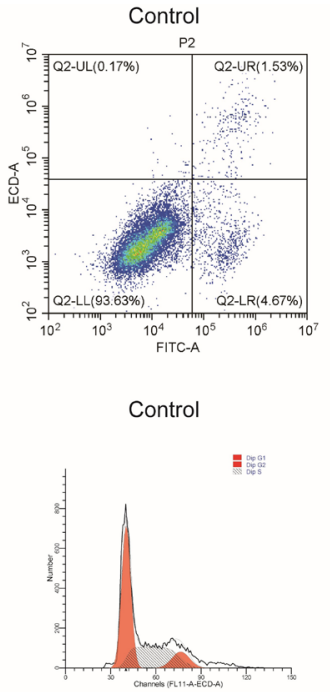

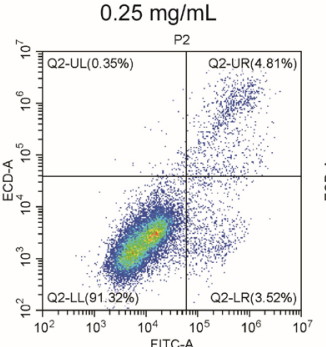

$0.25 \mathrm{mg} / \mathrm{mL}$

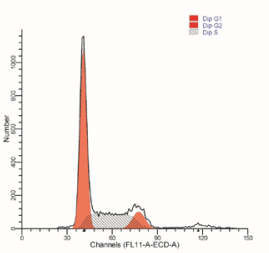

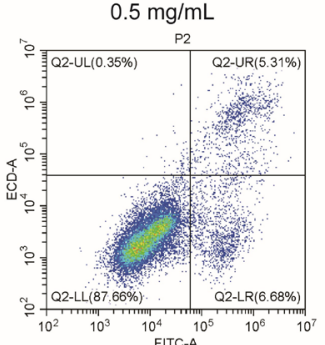

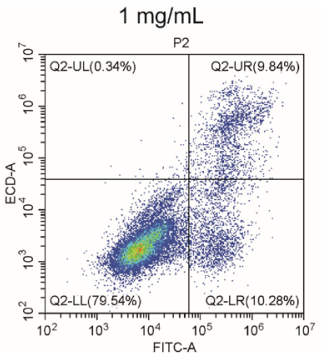

$0.5 \mathrm{mg} / \mathrm{mL}$

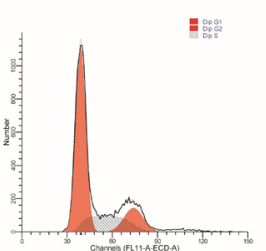

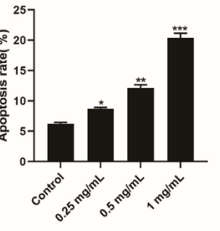

$1 \mathrm{mg} / \mathrm{mL}$

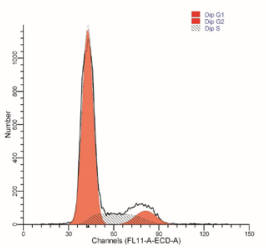

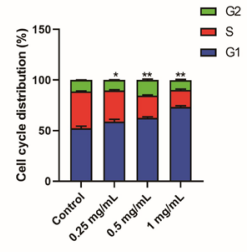

Figure 4. Effects of different concentrations of UA+Rg3-LIP on apoptosis rate and cell cycle of the HepG2 cells.

After being treated with different concentrations of UA+Rg3-LIP $(0.25 \mathrm{mg} / \mathrm{mL}, 0.5 \mathrm{mg} / \mathrm{mL}$, and $1 \mathrm{mg} / \mathrm{mL})$ for $48 \mathrm{~h}$, apoptosis $(\mathbf{A})$ and cell cycle (B) were detected by flow cytometry. ${ }^{*} P<0.05$ vs Control group; ${ }^{* *} P<0.01$ vs Control group; ${ }^{* * *} P<0.001$ vs Control group

and time-dependent manner, which is currently considered to be an effective anticancer drug in vitro (Ramos et al., 2008; Liu et al., 2014; Yie, Zhao et al., 2015). On the other hand, ginseng is a natural Chinese herbal plant, from which an effective chemical component called ginsenoside $\mathrm{Rg} 3$, one of the most common natural medicines, is extracted (Tan et al., 2011). Previous studies have shown that $\operatorname{Rg} 3$ has significant anticancer effects on various malignant tumors, such as the colon cancer (Kim et al., 2009), prostate cancer (Kim et al., 2004), breast cancer (Zhang et al., 2008), and lung cancer (Liu et al., 2009). In addition, ginsenoside $\operatorname{Rg} 3$ can inhibit the proliferation, adhesion, invasion, as well as metastasis of hepatoma cells, and induce cell death (Wen et al., 2008; Dogu \& Díaz, 2009; Yin \& Wang, 2015). Liposomes are biodegradable phospholipids without toxic and side effects on the human body. They have good targeting and permeability, which can minimize the toxic side effects of drugs and improve the efficacy of anti-cancer drugs. They are currently used as a more ideal drug carrier. In recent years, the development of Chinese medicine liposomes has become a hot topic in the study on the dosage forms of traditional Chinese medicine (Wu Y et al., 2006).

In the study presented here, UA+Rg3-LIP were successfully prepared. The particle size and surface potential of co-loaded liposomes and single liposomes were measured by confocal microscopy and potential analyzer, respectively. The assay results showed that the particle size of UA+Rg3-LIP was $181.7 \pm 4.36 \mathrm{~nm}$ and that of LIP was $163.5 \pm 3.92 \mathrm{~nm}$; the surface potential of $\mathrm{UA}+\mathrm{Rg} 3$-LIP was $-33.7 \pm 1.48 \mathrm{mV}$ and that of LIP was $-18.5 \pm 2.17 \mathrm{mV}$, which met the requirements of a passive targeting drug delivery system. Upon determination of the entrapment efficiency, it was found that the entrapment efficiency of UA in the co-loaded liposomes was $78.52 \%$, and that of $\operatorname{Rg} 3$ was $71.68 \%$. The release process of UA+Rg3-LIP prepared in this study revealed that the in vitro release rate of co-loaded liposomes in the artificial intestinal fluid was faster at $1-10 \mathrm{~h}$, but it slowed down after $10 \mathrm{~h}$ and approached $100 \%$ after $24 \mathrm{~h}$. This release behavior conformed to the first-order kinetic equation and the optimal model for UA+Rg3-LIP was the Higuchi equation. Then, the effect of co-loaded liposomes on liver cancer was examined by in vitro experiments, in which MT'T and flow cytometry revealed that co-loaded liposomes could effectively and efficiently inhibit the growth and proliferation of liver cancer cells, and significantly increase the apoptosis rate of HepG2 cells, while at the same time markedly raise the proportion of cells in the G0/G1 phase and decrease their proportion in the $\mathrm{S}$ phase, showing a certain concentration dependence. The above results illustrated that UA+Rg3LIP could inhibit proliferation and induce apoptosis of the hepatoma cells to achieve the anti-hepatoma killing effect. Studies have shown that UA or ginsenoside $\mathrm{Rg} 3$ inhibits HepG2 cell proliferation and promotes apoptosis by regulating the expression balance of $\mathrm{Bcl}-2, \mathrm{Bcl}-\mathrm{xl}$ and Bax of Bcl-2 family members (Tan et al., 2011; Zhang et al., 2012; Shanmugam et al., 2013). However, the specific mechanism of action of UA+Rg3-LIP on HCC needs further study.

\section{CONCLUSION}

In conclusion, in this study we have successfully prepared liposomes co-loaded with UA and $\operatorname{Rg} 3$, which can effectively inhibit proliferation of HepG2 and promote cell apoptosis. These liposomes also have a potential to serve as an efficient tumor-targeted drug delivery system.

\section{REFERENCES}

Commission CP (2015) Pharmacopoeia of the people's republic of china volume III (2015). China Medical Science Press

Dogu Y, Díaz J (2009) Mathematical model of a network of interaction between p53 and bcl-2 during genotoxic-induced apoptosis. Biophys Chem 143: 44-54. https://doi.org/10.1016/j.bpc.2009.03.012

Elmore S (2007) Apoptosis: A review of programmed cell death. Toxicol Pathol 35: 495-516. http://doi.org/10.1080/01926230701320337

He BC, Gao JL, Luo X, Luo J, Shen J, Wang L, Zhou Q, Wang YT, Luu HH, Haydon RC, Wang CZ, Du W, Yuan CS, He TC, Zhang BQ (2011) Ginsenoside rg3 inhibits colorectal tumor growth through the down-regulation of wnt/ß-catenin signaling. Int J Oncol 38: 437-445. https://doi.org/10.3892/ijo.2010.858

Hua Q, Hua H (2012) Research progress on anti - hepatoma mechanisms of ginsenoside rg3. China J Chinese Med 27: 266-269 
Jiang JW, Yu Y, Jiang YF, Tang ZQ, Liang YX, Liu LB, Tian GX, Wu JL (2018) Preparation of astragalus polysaccharide combined with doxorubicin liver targeting liposome and its anti-hepatoma effect. World Latest Med Inf 18: 221-222

Jiang JW, Chen XM, Chen XH, Zheng SS (2011) Ginsenoside rg3 inhibit hepatocellular carcinoma growth via intrinsic apoptotic pathway. World J Gastroenterol 17: 3605-3613. https://doi.org/10.3748/ wig.v17.i31.3605

Jiao F, Long L, Ding S, Xie X, Jia L, Lu F (2017) Complete genome sequencing and clinical analysis of intrahepatic hepatitis b virus cccdna from hcc. Microb Pathog 109: 49-55. https://doi.org/10.1016/j. micpath.2017.04.028

Khan K, Aqil M, Imam SS, Ahad A, Moolakkadath T, Sultana Y, Mujeeb M (2018) Ursolic acid loaded intra nasal nano lipid vesicles for brain tumour: Formulation, optimization, in-vivo brain/plasma distribution study and histopathological assessment. Biomed Pharmacother 106: 1578-1585. https://doi.org/10.1016/j.biopha.2018.07.127

Kim GH, Kan SY, Kang H, Lee S, Ko HM, Kim JH, Lim JH (2019) Ursolic acid suppresses cholesterol biosynthesis and exerts anticancer effects in hepatocellular carcinoma cells. Int J Mol Sci 20. https://doi.org/10.3390/ijms20194767

Kim HS, Lee EH, Ko SR, Choi KJ, Park JH, Im DS (2004) Effects of ginsenosides $\mathrm{rg} 3$ and $\mathrm{rh} 2$ on the proliferation of prostate cancer cells. Arch Pharm Res 27: 429-435. https://doi.org/10.1007/ BF02980085

Kim SM, Lee SY, Yuk DY, Moon DC, Choi SS, Kim Y, Han SB, Oh KW, Hong JT (2009) Inhibition of nf-kappab by ginsenoside $\mathrm{rg} 3$ enhances the susceptibility of colon cancer cells to docetaxel. Arch Pharm Res 32: 755-765. https://doi.org/10.1007/s12272-009-1515-4

Laszczyk MN (2009) Pentacyclic triterpenes of the lupane, oleanane and ursane group as tools in cancer therapy. Planta Med 75: 15491560. https://doi.org/10.1055/s-0029-1186102

Lee JY, Yang H, Yoon IS, Kim SB, Ko SH, Shim JS, Sung SH, Cho HJ, Kim DD (2014) Nanocomplexes based on amphiphilic hyaluronic acid derivative and polyethylene glycol-lipid for ginsenoside rg3 delivery. J Pharm Sci 103: 3254-3262. https://doi.org/10.1002/ jps. 24111

Liu L, Zhang J, Li M, Zhang X, Zhang J, Li Z, Wang L, Wu J, Luo C (2014) Inhibition of hepg 2 cell proliferation by ursolic acid and polysaccharides via the downregulation of cyclooxygenase-2. Mol Med Rep 9: 2505-2511. https://doi.org/10.3892/mmr.2014.2059

Liu TG, Huang Y, Cui DD, Huang XB, Mao SH, Ji LL, Song HB, Yi C (2009) Inhibitory effect of ginsenoside $\mathrm{rg} 3$ combined with gemcitabine on angiogenesis and growth of lung cancer in mice. $B M C$ Cancer 9: 250. https://doi.org/10.1186/1471-2407-9-250

Lu P, Su W, Miao ZH, Niu HR, Liu J, Hua QL (2008) Effect and mechanism of ginsenoside $\mathrm{rg} 3$ on postoperative life span of patients with non-small cell lung cancer. Chin J Integr Med 14: 33-36. https://doi.org/10.1007/s11655-007-9002-6

Lui HF (2011) Screening for hepatocellular carcinoma. Int J Hepatol 2011: 363151. https://doi.org/10.4061/2011/363151

Ma NH, Lu L, Ding Y, Zhang LJ, Chen Y, Zhang T (2019) Preparation of doxorubicin hydrochloride and timosaponin aIII co-loaded liposomes and determination of encapsulation efficiency. Chinese Trad Herbal Drugs 50: 69-75

Musacchio T, Torchilin VP (2011) Recent developments in lipid-based pharmaceutical nanocarriers. Front Biosci (Landmark Ed) 16: 13881412. https://doi.org/10.2741/3795
Ngo SN, Williams DB, Head RJ (2011) Rosemary and cancer prevention: Preclinical perspectives. Crit Rev Food Sci Nutr 51: 946-954. https://doi.org/10.1080/10408398.2010.490883

Ou CF, Liang YL, Shen SW, Han X (2011) Preparation of liposomal in curcumin using ethanol injection method. Guangxi Agric Sci 42: 1259-1262

Ramos AA, Lima CF, Pereira ML, Fernandes-Ferreira M, Pereira-Wilson C (2008) Antigenotoxic effects of quercetin, rutin and ursolic acid on hepg2 cells: Evaluation by the comet assay. Toxicol Lett 177: 66-73. https://doi.org/10.1016/j.toxlet.2008.01.001

Shanmugam MK, Dai X, Kumar AP, Tan BK, Sethi G, Bishayee A (2013) Ursolic acid in cancer prevention and treatment: Molecular targets, pharmacokinetics and clinical studies. Biochem Pharmacol 85: 1579-1587. https://doi.org/10.1016/j.bcp.2013.03.006

Shanmugam MK, Nguyen AH, Kumar AP, Tan BK, Sethi G (2012) Targeted inhibition of tumor proliferation, survival, and metastasis by pentacyclic triterpenoids: Potential role in prevention and therapy of cancer. Cancer Lett 320: 158-170. https://doi.org/10.1016/j. canlet.2012.02.037

Sun S, Guan Q, Shang E, Xiao H, Yu X, Shi L, Zhao C, Guo Y, Lv S, Li Y (2020) Hyaluronic acid-coated nanostructured lipid carriers for loading multiple traditional chinese medicine components for liver cancer treatment. Pak J Pharm Sci 33: 109-119

Tan W, Lu J, Huang M, Li Y, Chen M, Wu G, Gong J, Zhong Z, Xu Z, Dang Y, Guo J, Chen X, Wang Y (2011) Anti-cancer natural products isolated from chinese medicinal herbs. Chin Med 6: 27. https://doi.org/10.1186/1749-8546-6-27

Wang L (2010) Research progress on preparation methods of liposome. Northwest Pharmac J 25: 2-4

Wen H, Zeng W, Fang HE (2008) Inhibitory effect of ginsenoside $\mathrm{rg} 3$ on transplanted human hepatic carcinoma in nude mice. Modern Hospital 8: 14

Wu Y, Ye H, Wang J, Du Y, Li F, Bing Z, Fang J (2006) Preparation of acanthophopanaxenticosus liposomes and its therapeutic effect on implanted hepatocellular carcinoma in mice. Chinese Arch Trad Chinese Med 24: 1029-1030

Yie Y, Zhao S, Tang Q, Zheng F, Wu J, Yang L, Deng S, Hann SS (2015) Ursolic acid inhibited growth of hepatocellular carcinoma hepg2 cells through ampk $\alpha$-mediated reduction of DNA methyltransferase 1. Mol Cell Biochem 402: 63-74. https://doi.org/10.1007/ s11010-014-2314-X

Yin TX, Wang YY (2015) Effect of ginsenoside rg3 on the proliferati on,adhesion,migration and apoptosis of human hepatoma cell lines and the mechanism. Basic Clin Med 35: 303-307

Zhan L, Yi YM (2008) Preparation and drug release of ursolic acid sustained-release tablets. Herald Med 27: 587-588

Zhang C, Liu L, Yu Y, Chen B, Tang C, Li X (2012) Antitumor effects of ginsenoside $\mathrm{rg} 3$ on human hepatocellular carcinoma cells. Mol Med Rep 5: 1295-1298. https://doi.org/10.3892/mmr.2012.808

Zhang NS, Zhang XH, Li WF (2006) Research progress of ginsenoside rg3. Herald Med 25: 687-689

Zhang Q, Kang X, Yang B, Wang J, Yang F (2008) Antiangiogenic effect of capecitabine combined with ginsenoside $\mathrm{rg} 3$ on breast cancer in mice. Cancer Biother Radiopharm 23: 647-653. https://doi. org/10.1089/cbr.2008.0532 